\title{
Performance Evaluation of a Gas Turbine Power Plant by the application of Compressor Off-Line and On-Line Water Washing Techniques. (A Case Study of 450MW Sapele Power Station in Delta State, Nigeria)
}

\author{
A. J. Ujam, P. O. Ekere, and T. O. Chime. \\ a. Department of Mechanical and Production Engineering, Enugu State University of Science and Technology, Enugu. \\ b. Department of Engineering Research, Development and Production, Project Development Institute (PRODA), Enugu. \\ c. Department of Chemical Engineering, Enugu State University of Science and Technology, Enugu.
}

\begin{abstract}
The aim of this research is to appraise the performance of a gas turbine engine through the use of compressor online and off-line water washing optimization maintenance technique. Data were collected from the power generation station, Sapele, Delta State over a period of twenty four months (two yrs) from two gas turbine engines "GT1 \& GT2", of the same capacity, and at the same location, commissioned the same time. GT1 uses both compressor online and off-line water washing optimization technique, while GT2 uses only offline water washing optimization technique. The data collected were analyzed. It shows that before the offline water washing exercise, GT2 were operating at $8.47 \mathrm{bar}$, as depicted in trend for GT2. The compressor outlet pressure is an indication of fouling, as this menace causes a reduction of the pressure. The application of online water washing to GT1 increases the pressure to 9.99 bar. The trend shows that the use of online water washing improved the firing temperature of GT1 by $6.96 \%$. The trend shows that the use of online water washing improved the Network output of GT1 by $6.42 \%$. The network output momentarily decreases due to redeposition of foulants in the later stages of the compressor indicating inappropriate application of washing procedure. GT1 yielded compressor efficiency of $81.6 \%$ as a result of online water washing against the $78.5 \%$ of GT2. It also implies that the air pumping capacity of the GT1 compressor has increased. It is observed that a small change of the compressor efficiency have a significant effect on the overall GT performance and efficiency. GT1 has compressor efficiency of $81.6 \%$ which resulted to overall GT efficiency of $28.3 \%$ against $27.7 \%$ of GT2. GT1 fuel consumption was less by $2.14 \mathrm{~kg} / \mathrm{kwh}$ as a result of online water washing against the $18.55 \mathrm{~kg} / \mathrm{kwh}$ of GT2
\end{abstract}

Key words: - Gas Turbine, Compressor, Pressure, Online washing, Offline washing, Fuel Consumption, Efficiency, Fouling.

\section{INTRODUCTION}

Power generation is an important issue today, prompt by the zeal to have an efficient energy sector which is generally regarded as a pre-requisite for the realization of goals and objectives of economic reforms such as wealth creation, employment generation, poverty reduction and eradication. In the face of these challenges, government after government have not lacked in the amount of pious resolves to steer the nation on the path of reform that would dramatically cure the apparently intractable energy problem. The growth in electricity demand being experienced in Nigeria has resulted in the need to build power plants that generate maximum power output overtime, with a reduction in down-time. Due to less installation time, low installation cost and availability of natural gas in the country, many states of the country and private establishments are currently building gas turbine power plants to meet this demand. However, one major disadvantage that penalizes the gas turbine performing is the adverse effect of the environment on the gas turbine power output and efficiency. Gas turbines designed to operate at maximum efficiency at standard ambient temperatures and relative humidity may tend to reduce in performance due to adaptation problems resulting from variation in weather conditions as they are installed at different locations.

The ability to predict the behaviour of a gas turbine engine and optimize its performance is critical in economic, thermal and condition monitoring studies. To utilize the high economic and energy saving potential of a gas turbine engine in their simple and combined cycles, it is important to identify their optimal design parameters and determine the impact of the deviation of these parameters from the standard conditions, on the overall performance of the engine. Compressor fouling has been identified as one of the major sources of this deviation and gas- turbine degradation. Thus compressor online water washing optimization technique is often applied to recover gas turbine performance loss. 


\section{Offline Washing:}

Offline washing is a typical "soak and rinse" procedure for which the gas turbine must be shut down and cooled. The compressor is rotated at crank-speed while a cleaning fluid is injected via the injector nozzles, installed in the air inlet plenum.

Offline washing is almost always carried-out with the aid of detergent, and extremely effective power recovery can usually be achieved. However, it is important that the manufacturer's recommendations are followed with respect to water quality, detergent/water ratio and other operating procedures. The downtime for a crank wash depends mainly on the time it takes for cooling the engine. Larger heavy-duty engines can take 8 to 10 hours to cool whereas on light engines only 1.5 to 3 hours may be needed because of the low metal mass.

\section{Online Washing:}

The primary objective of online washing is to extend the operating period between offline washes by minimizing the build-up of deposits in the compressor, and thereby reducing the ongoing incremental power losses. Online washing is performed with the unit in full operation, and under load. Outages or shutdown period are not required. The procedure involves the injection of a mixture of water and chemical detergent via atomizing spray nozzles positioned around the compressor air intake plenum. This is followed by a flushing period using pure water. With online cleaning, it is mandatory to use demineralized water for preparing the cleaning fluid and for flushing. This is because the turbine is in operation, and high temperature corrosion damage may occur if sodium or other contaminant metals enter the combustion path. An online washing program should always be started on a clean engine, after an overhaul or crank wash. It is not recommended to perform online washing on a heavily fouled engine, because large quantities of dirt removed from the front stages would instantaneously pass through the compressor. Therefore, after starting an online wash program, the time intervals between subsequent washings should be kept short: approximately every three days to weekly, depending on the local conditions. The duration of each online wash can also be varied according to the degree of fouling, engine size, and plant experiences, etc. Typical online cleaning cycles are in the order of 10 to 20 minutes and a flushing or rinsing cycle (using only demineralized water) of about the same duration should be applied after each cleaning cycle with detergent - for example, 10 to 20 minutes flushing cycle without detergent.

Optimal compressor cleaning can normally be achieved by adopting a combined program of regular and routine online washing, plus periodic offline washing during planned outages.

Correct application of these optimization techniques allows the turbine performance loss to be kept close to that due to aging of the machine, identified as non-recoverable degradation.

The use of Hot water for offline washing requires that compressor wash skids should be equipped with a heating system, insulated tanks, and insulated piping, etc, and this significantly increase acquisition costs, equipment maintenance cost and operating cost. Engdar, et al. [1] conducted computational fluid Dynamics (CFD) studies on hot water injection for offline compressor washing. The author concluded that, regardless of its inlet temperature, i.e. "the inlet temperature of the washing fluid", injected wash fluid is cooled down to ambient air temperature well before the spray reaches the inlet guide vanes. The author indicates that heating the wash fluid may serve little benefit, despite that it is conceivable that hot water may improve cleaning efficiency by helping to soften deposits and increase solubility.

Foulant deposits often contain sodium and potassium chlorides. These combine with water to form an aggressive solution that promotes pitting corrosion of the blades. Corrosion is rarely observed beyond the eight compressor stage, as no moisture will survive at the temperature beyond this point.

Cyrus B. Meher - Homji et al [2] studied the Environmental Impact of Online Washing. According to their study, online washing will create a small increase in $\mathrm{CO}$ emission due to disturbance of the combustion conditions associated with the injection of water. They concluded that this should not however, be misinterpreted as a reason not to perform online cleaning, since the emission increase will be short-lived (only for the duration of the wash and rinse cycle) and is normally classified as a "transient condition". On the other hand, according to their study, low mass flow online injection system will have less impact on CO emissions than high mass flow designs, because less water is injected. Also the use of detergent during online washing have an insignificant impact on emissions, compared to the effect of water alone.

(Ogbonnaya, Ezenwa [3] studied the optimization of the performance of gas turbine engines. His study recommended that operators should perform a combination of compressor hand cleaning, offline and online washing simultaneously. He carried out a fifteen-week comparative performance analysis of a gas turbine on industrial duty for electricity generation in Sapele, Delta State of Nigeria.

Elisabeth Syverud [4] conducted a detailed analytical investigation into the deterioration of turbine operation including drop in compressor efficiency, fouling, first stage nozzle distortion, internal bleed seal deterioration, drop in turbine efficiency, inlet filter fouling, and low fuel heating value. These parameters were 
examined to study the effect on the turbine operating line. His study concluded that compressor fouling has a pronounced effect on the operating line and causes the movement of the operating line toward the surge line.

The susceptibility of gas turbine axial flow compressor to fouling (as a function of gas turbine design parameters) has been studied by Tarabrin, et al. [5]. Their work concluded that the rate of particle deposition on blades increases with a growing angle of attack and that smaller engines exhibit a high sensitivity to fouling than larger engines. Further, the sensitivity to fouling increases with increasing compressor stage head $(\mathrm{Cp} \Delta \mathrm{T})$. Design parameters such as air inlet velocity at the inlet guide vanes, compressor pressure ratio, aerodynamic \& geometrical characteristics will determine the inherent sensitivity to fouling for a specific compressor design. Tarabrin, et al. [5] have suggested that the index of axial compressor sensitivity to fouling can be represented mathematically as:

$$
I S F=\frac{m C_{p} \Delta T_{\text {stage }}}{\left(1-r_{h}{ }^{2}\right) D_{c}^{3}} \times 10^{-6}
$$

Where $r_{h}=$ Hub/tip ratio for the first stage.

$\mathrm{D}_{\mathrm{c}}=$ Tip diameter of axial compressor first stage, $\mathrm{m}$.

$\mathrm{C}_{\mathrm{p}}=$ Specific heat $(\mathrm{J} / \mathrm{kg} \mathrm{k})$.

$\Delta \mathrm{T}_{\text {stage }}=$ Average total temperature rise/stage, ${ }^{0} \mathrm{c}$.

According to Tarabrin, et al. [5] assuming engines operating under similar environmental conditions and with the same level and quality of air filtration, engines with higher ISF values would exhibit a greater reduction of air flow, pressure and efficiency than engines with a lower ISF.

An empirical formular proposed by Tarabrin, et al. [5], for fouling Degradation Rate is given by

$$
\Delta \text { Power }=\mathrm{a}\left[1-\mathrm{e}^{-\mathrm{bt}}\right]
$$

Where: $\mathrm{a}=0.07 ; \mathrm{b}=0.005 ; \mathrm{t}=$ time

According to his study, fouling tends to occur during initial operation and roughly follows an exponential law.

According to Elizabeth Syverud \& Lars E. Bakken [6] successful online washing requires close attention to the gas turbine flow path geometry, the operating profile and the nature of the airborne fouling at the compressor inlet (after filtration). According to their study, there is currently no consensus on a recommended method for effective online water washing. System properties like droplet size, droplet velocity and fluid injection rate vary from one system to another. This makes it difficult for operators to select the best online water wash system for their application. They recommend that high water flow rate and moderate droplet size is the most significant parameter for efficient online water wash. But low flow rate and smaller droplets causes redeposition of the fouling in the aft stages, and increased water injection time cannot compensate for low flow rates.

Elizabeth Syverud and Lars E. Bakken carried-out online water wash test of a GE J85-13 jet engine at the test facilities of the Royal Norwegian Air Force. The engine performance was deteriorated by injecting atomized saltwater at the engine inlet. Then, the engine was online washed with water injected at three different droplet sizes $(25,75$, and $200 \mu \mathrm{m})$ and at water-to-air ratios ranging from $0.4 \%$ to $3 \%$ by mass. Engine performance was measured using standard on-engine instrumentation. According to their study, $75 \mu \mathrm{m}$ droplets are the most effective in recovering the overall engine performance, and in cleaning the fourth-stage; however, the smaller droplets seem to redeposit the fouling in the sixth-stage and cause increased sixth-stage deterioration The water was supplied at 24 bar pressure and a 5 minute online wash completely clean the compressor of salt deposit.

This study therefore focuses on the performance evaluation of two gas turbine plants in the Niger Delta region of Nigeria (Sapele).

According to Hart [7], Power generating gas turbine sets installed in Niger Delta area were inefficient and problematic. Among the serious problems that have been common are failures of bladings, ruptured combustion chambers, excessive vibration, all which occur after relatively short periods of operation of the sets. The incidence compressors stalls, surges are also common. According to his study, industrial gas turbines are generally designed with temperate region climatic and environmental condition, since most of the users of the machines are in that region. The ambient conditions in the temperate regions are also relatively closer to those required for optimum performance of gas turbines. However Niger Delta lies on the equatorial rain forest region which has climatic conditions that are sharply different from those of temperate regions. According to his study, a degree centigrade $\left(1^{\circ} \mathrm{C}\right)$ rise in ambient temperature above ISO condition could be responsible for the following: $0.83 \%$ reduction in power output, $0.17 \%$ increase in heat rate and $0.40 \%$ decrease in required air flow rate. His study reveals that GTs is more sensitive to initial fouling than the later one. Changes in power output 
and compressor isentropic efficiency fell by as much as between $3 \%$ to $5 \%$ and $5 \%$ to $7 \%$ respectively in the first 500 hours of operation after cleaning but changed by as little as $2 \%$ to $3 \%$ and $3 \%$ to $5 \%$ respectively for periods of 4000 hours or more after the initial 500 hours. Thus operating gas turbines designed with temperate region conditions in Niger Delta will experience performance problem if appropriate remedies are not put in place.

\section{METHODOLOGY AND RESULTS}

Data were collected from daily log sheets and annual generation reports at the instrumentation Department of the Station. In processing the data average daily values were obtained as appropriate. Using the same method, average values for the various weeks, months and the years were obtained.

GT1 were maintained by weekly online washing and periodic offline washing (six months interval), whereas GT2 were maintained by periodic offline washing only (four months interval). From table $7 \& 8$ below, $\mathrm{T}_{1}, \mathrm{~T}_{2}$, $\mathrm{T}_{3}, \mathrm{~T}_{4}, \mathrm{P}_{1} \& \mathrm{P}_{2}$ were collated from the generation station over a period of twenty-four months starting from May 2010 to April 2012. While other variables $\left(W_{c}, W_{t}, W_{\text {net }}, \eta_{c} . \eta_{\mathrm{o}}, S F C\right)$, were derived from equation (19) to (32) using Scilab programming language. For Compression process $\quad \mathrm{Cp}=1.005 \mathrm{~kJ} / \mathrm{kgk}, \gamma=1.4$

For Combustion process \& Expansion process $\mathrm{Cp}=1.11 \mathrm{~kJ} / \mathrm{kgk}, \gamma=1.3$

\subsection{Description of the GT (GE Frame PG9171E):}

The GT is a single shaft, three bearing heavy duty industrial unit with a 17 - stage axial flow compressor (equipped with eight (8) plugged nozzles located in the forward wall of the compressor inlet bell mouth for off-line washing and sixteen (16) plugged nozzles for on-line washing located as follows: eight (8) on the forward wall and back wall of the compressor inlet bell mouth respectively), can-annular type combustor and a 3- stage axial flow turbine. The rotor assembly consisting of one compressor rotor joined to one turbine rotor by a flanged joint, and lays on three journal bearings (two elliptical and one tilting pad type). Two thrust bearings; one Kingsbury type (loaded) and one tilting pad type (unloaded) are also provided. The engine is designed for $3000 \mathrm{rpm}$ nominal speed, to be directly coupled to a two-pole synchronous electric generator. The gas turbine unit casings and shells are split and flanged horizontally for convenience of disassembling.

Table 1:Typical Water Quality Requirements for an on/offline washing

\begin{tabular}{|c|c|c|}
\hline \multicolumn{2}{|c|}{ Offline Washing } & Quality Specification \\
\hline & $\begin{array}{l}\quad \text { Total solids (dissolved and undissolved) } \\
\text { Total alkali metal } \\
\text { Other metals } \\
\text { pH (determined by glass electrode) }\end{array}$ & $\begin{array}{l}100 \mathrm{ppm} \\
25 \mathrm{ppm} \\
1.0 \mathrm{ppm} \\
6.5 \text { to } 7.5\end{array}$ \\
\hline \multicolumn{2}{|c|}{ Online Washing } & Quality Specification \\
\hline & $\begin{array}{l}\text { Total solids (dissolved \& undissolved) } \\
\text { Total alkali metal \& other metals } \\
\text { pH (determined by glass electrode) }\end{array}$ & $\begin{array}{l}5 \mathrm{ppm} \\
0.5 \mathrm{ppm} \\
6.5 \text { to } 7.5\end{array}$ \\
\hline
\end{tabular}

Hint: ppm = part per million

Table 2: Technical specifications of GE frame 9E gas turbine:

\begin{tabular}{|l|l|l|}
\hline Parameter & Design Specification & ISO Specification \\
\hline Atmospheric Pressure & 1.013 bar & $1.013 \mathrm{bar}$ \\
\hline Design Ambient Temperature & $50^{\circ} \mathrm{C}=323^{\circ} \mathrm{K}$ & $15^{\circ} \mathrm{C}=288^{\circ} \mathrm{K}$ \\
\hline Minimum Ambient Temperature & $-5^{\circ} \mathrm{C}=268^{\circ} \mathrm{K}$ & - \\
\hline Maximum Ambient Temperature & $55^{\circ} \mathrm{C}=328^{\circ} \mathrm{K}$ & - \\
\hline Design Relative Humidity & $30 \%$ & $60 \%$ \\
\hline Minimum Relative Humidity & $5 \%$ & - \\
\hline Maximum Relative Humidity & $95 \%$ & - \\
\hline Basic Wind Speed & $3.2 \mathrm{~m} / \mathrm{s}$ & $3.2 \mathrm{~m} / \mathrm{s}$ \\
\hline
\end{tabular}


Table 3: Estimated Performance in Full load Operation:

\begin{tabular}{|l|l|l|l|l|}
\hline Parameter & Units & Base & Base & Base \\
\hline Ambient Temperature & ${ }^{\circ} \mathrm{C}$ & -5 & 50 & 55 \\
\hline Relative Humidity & $\%$ & 30 & 30 & 30 \\
\hline Exhaust Static Pressure & $\mathrm{mmH}_{2} \mathrm{O}$ & 106.2 & 75.4 & 72.3 \\
\hline Evaporative Cooler Status & - & Off & on & On \\
\hline Evaporative Cooler Effectiveness & $\%$ & - & 85 & 85 \\
\hline Fuel Type & - & Natural Gas & Natural Gas & Natural Gas \\
\hline Fuel Temperature & ${ }^{\circ} \mathrm{C}$ & 42 & 42 & 42 \\
\hline Fuel Lower Caloric Value (LHV) & $\mathrm{kJ} / \mathrm{kg}$ & 46670 & 46670 & 46670 \\
\hline Gross Output & $\mathrm{Kw}$ & 140500 & 108200 & 104600 \\
\hline Gross Heat Rate $(\mathrm{LHV})$ & $\mathrm{kJ} / \mathrm{kwh}$ & 10680 & 11290 & 11380 \\
\hline Heat Consumption & $\mathrm{GJ} / \mathrm{h}$ & 1500.5 & 1221.6 & 1190.3 \\
\hline Exhaust flow & $\mathrm{X} 10^{3} \mathrm{~kg} / \mathrm{h}$ & 1654.7 & 1380.3 & 1349.9 \\
\hline Exhaust Temperature & ${ }^{\circ} \mathrm{C}$ & 499.4 & 532.4 & 536.1 \\
\hline Exhaust Energy & $\mathrm{GJ} / \mathrm{h}$ & 893.8 & 733.2 & 718.9 \\
\hline Water flow & $\mathrm{Kg} / \mathrm{h}$ & 22453 & 13989 & 11816 \\
\hline
\end{tabular}

Table 4: Performance Data @ ISO Specification:

\begin{tabular}{|l|l|}
\hline Parameter & Specification \\
\hline Power Output (Generator Terminals) & $123.4 \mathrm{Mw}$ \\
\hline Efficiency (Generator Terminals) & $33.8 \%$ \\
\hline Rotor Speed & $3000 \mathrm{rpm}$ \\
\hline Atmospheric Pressure & $1.013 \mathrm{bar}$ \\
\hline Ambient Temperature & $15^{\circ} \mathrm{C}$ \\
\hline Relative Humidity & $60 \%$ \\
\hline Pressure loss @ air intake filter & $.009 \mathrm{bar}$ \\
\hline Air Flow Rate & $401.7 \mathrm{~kg} / \mathrm{s}$ \\
\hline Compressor outlet Temperature & $355^{\circ} \mathrm{C}$ \\
\hline Compressor outlet Pressure & $12.663 \mathrm{bar}$ \\
\hline Pressure Ratio & 12.5 \\
\hline Combustion Chamber inlet Pressure & $12.463 \mathrm{bar}$ \\
\hline Lower Calorific Value of Fuel & $46670 \mathrm{~kJ} / \mathrm{kg}$ \\
\hline Type of Fuel & $\mathrm{Natural} \mathrm{Gas}$ \\
\hline Fuel Gas Flow Rate & $7.8 \mathrm{~kg} / \mathrm{s}$ \\
\hline Turbine inlet Temperature & $1124^{\circ} \mathrm{C}$ \\
\hline Turbine inlet Pressure & $12.363 \mathrm{bar}$ \\
\hline Turbine outlet Temperature & $551^{\circ} \mathrm{C}$ \\
\hline Turbine outlet Pressure & $1.018 \mathrm{bar}$ \\
\hline Exhaust Gas Flow Rate & $409.5 \mathrm{bar}$ \\
\hline Pressure loss @ Exhaust & $0.013 \mathrm{bar}$ \\
\hline For Compression process & $\mathrm{C}_{\mathrm{p}}=1.005 \mathrm{~kJ} / \mathrm{kgk}, \gamma=1.4$ \\
\hline For Combustion process & $\mathrm{Cp}^{2}=1.1557 \mathrm{~kJ} / \mathrm{kgk}$, \\
\hline For Expansion process & $\mathrm{C}_{\mathrm{p}}=1.11 \mathrm{~kJ} / \mathrm{kgk}, \gamma=1.3$ \\
\hline
\end{tabular}

\subsection{Design Thermodynamic Cycle of GE frame PG9171E GT:}

According to the specification of the manufacturers the GE frame PG9171E GT is to be operated on a Brayton (Joule) open cycle. From the design specifications, air is to be ingested into the compressor from the atmosphere of pressure $1.013 \mathrm{bar}$ and $15^{\circ} \mathrm{C}$ and compressed to a pressure of $12.663 \mathrm{bar}$, the air temperature rising to $355^{\circ} \mathrm{C}$. A pressure loss of 0.2 bar occurs in the duct between the compressor and the combustion chamber bringing the inlet pressure of the compressed air into the combustion chamber to $12.463 \mathrm{bar}$. In the combustion chamber a loss in pressure occurs due to the aerodynamic resistance of flame-stabilization and mixing effect and the momentum change produced by the exothermal reaction, bringing the pressure to 12.363 bar and the temperature to $1124^{\circ} \mathrm{C}$. In the turbine the combustion products are expanded and exhausted at a pressure and temperature of 1.018 bar and $551^{\circ} \mathrm{C}$ respectively.

The mass flow rate of air ingested into the compressor is $401.7 \mathrm{~kg} / \mathrm{s}$ and a reduction in pressure of about 0.009 bar is expected to occur as the air passes through the filtration process. The fuel for combustion is natural 
gas with lower calorific value of about $46670 \mathrm{~kJ} / \mathrm{kg}$ and the fuel should come in at the $7.8 \mathrm{~kg} / \mathrm{s}$ while the total mass of the exhaust gas is about $409.5 \mathrm{~kg} / \mathrm{s}$.

For thermodynamic analysis, a simplification will be made by assuming that the chemical energy released in the combustion is equivalent to a transfer of heat at constant pressure to a working fluid of constant mean specific heat. This simplified approach allows the actual process to be compared with the ideal and to be represented on a T-s diagram. Neglecting the pressure loss in the combustion chamber the cycle may be drawn on a $\mathrm{T}$-s diagram as shown
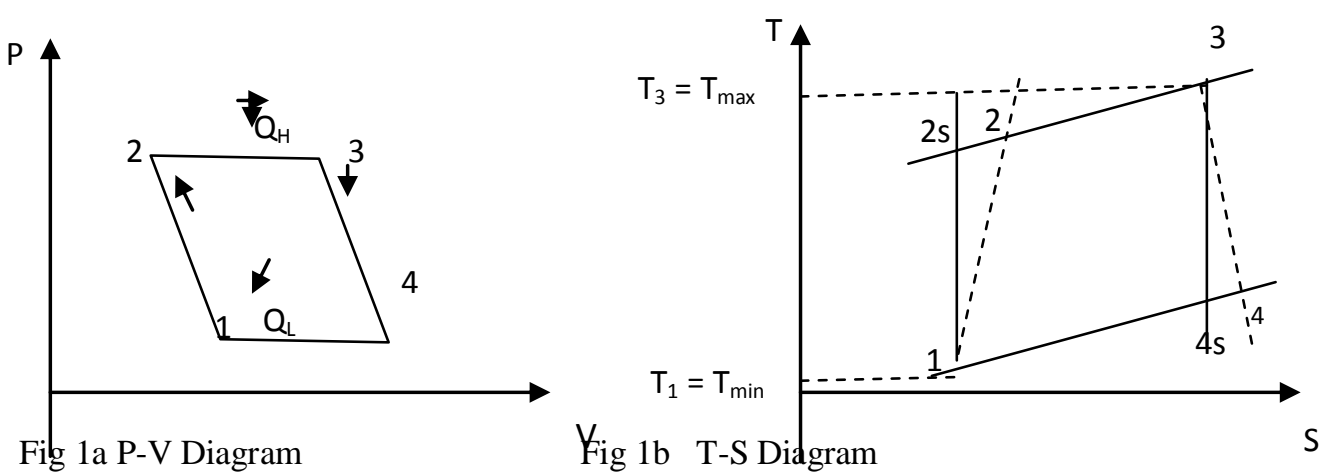

From the T-s diagram the cycle consists of the following processes:

Process 1=>2: Irreversible adiabatic compression from $\mathrm{P}_{1}$ to $\mathrm{P}_{2}$.

Process 2=>3: Constant pressure heat addition from $T_{2}$ to $T_{3}$.

Process 3=>4: Irreversible adiabatic expansion from $\mathrm{P}_{3}$ to $\mathrm{P}_{4}$.

Process $1=>2 s$ : Isentropic (ideal) compression $b / w$ pressure $P_{1}$ and $P_{2}$.

Process 3=>4s: Isentropic (ideal) expansion $\mathrm{b} / \mathrm{w}$ pressure $\mathrm{P}_{3}$ and $\mathrm{P}_{4}$.

\subsection{The Climatic and Environmental Conditions of the Sapele Power Station:}

Sapele Power Station is located at the Niger Delta area which lies between about latitude $4^{0} \mathrm{~N}$ and $6^{0} \mathrm{~N}$ and about longitude $5^{0} \mathrm{E}$ and $8^{0} \mathrm{E}$ covering all Rivers, Bayelsa and Delta States as well as part of Edo, Ondo, Akwa-Ibom, Imo and Abia States of Nigeria.

The vegetation is generally that of equatorial rain forest. Basically, there are two seasons - the wet (April to September) and the dry (October to March). However, rain falls almost throughout the year. The mean annual rainfall is 3,000 millimeter $(\mathrm{mm})$ while the mean monthly rainfall for the wet and dry seasons are about $500 \mathrm{~mm} \& 125 \mathrm{~mm}$ respectively, the mean daily temperature is $30^{\circ} \mathrm{C}$ while the maximum and minimum temperatures are about $40^{\circ} \mathrm{C}$ and $20^{\circ} \mathrm{C}$ respectively. The relative humidity of the area is rarely close to $30 \%$ (the design specification for the operation GE Frame $9 \mathrm{E}$ gas turbine) even during the dry season. In the wet season, the south-west wind from the Atlantic Ocean is predominant while during a good part of the dry season, the north-east trade wind from the Sahara Desert deposits its dust as it sweeps through the area. Dust deposits, which are regarded as negligible during the wet or rainy reason, can be as high as 100 milligram per square meter $\left(\mathrm{mg} / \mathrm{m}^{2}\right)$ of surface area. Between December and February of the harmattan period, the dust concentration can be as high as $20,000 \mathrm{mg} / \mathrm{m}^{2}$ especially during time of sand storms. Dust sizes may vary from fine to coarse and the aggressiveness of particles could be quite high, especially because of the location of oil-field that dotted the area.

The monthly average daily temperature $\dot{\mathrm{T}}\left({ }^{0} \mathrm{C}\right)$ and relative humidity $\dot{H}(\%)$ for the years under investigation is shown in table 5

Table 5: Monthly average daily temperature $\dot{\dagger}(\mathrm{C})$ ) and relative humidity $\mathrm{H}(\%)$

\begin{tabular}{|c|c|c|c|c|c|c|c|c|c|c|c|c|c|}
\hline Parameter & Year & $\operatorname{Jan}$ & Feb & Mar & Apr & May & Jun & Jul & Aug & Sep & Oct & Nov & Dec \\
\hline \multirow{3}{*}{$\begin{array}{l}\text { Monthly average } \\
\text { daily temp. } \dagger(O C)\end{array}$} & 2010 & 26.5 & 27.5 & 28.4 & 26.7 & 25.8 & 24.8 & 24.0 & 23.9 & 24.6 & 24.7 & 25.7 & 26.7 \\
\hline & & 27.3 & 28.6 & 29.0 & 28.1 & 26.9 & 5.4 & 24.5 & 24.3 & 4 & 25.3 & 27.5 & 26.5 \\
\hline & 2012 & 26.2 & 27.6 & 28.7 & 27.2 & 26.5 & 5.4 & 24.6 & 23.8 & 24.6 & 3 & 6.6 & 6.1 \\
\hline \multirow{3}{*}{$\begin{array}{l}\text { Monthly average } \\
\text { daily rel. humidity } \\
\dot{H}(\%)\end{array}$} & 2010 & 61.0 & 67.8 & 63.9 & 73.2 & 77.9 & 80.1 & 83.9 & 84.7 & 82.4 & 81.6 & 62.8 & 52.7 \\
\hline & 2011 & 54.1 & 59.8 & 58.3 & 69.7 & 76.7 & 80.9 & 82.0 & 83.6 & 82.8 & 79.9 & 78.7 & 49.7 \\
\hline & 2012 & 35.2 & 67.1 & 65.5 & 72.1 & 76.1 & 79.4 & 81.1 & 83.8 & 81.8 & 79.1 & 66.1 & 37.3 \\
\hline
\end{tabular}


2.3 Climatic Parameters Analysis:

Table 6: Average values, total average values and range values of the climatic parameters.

\begin{tabular}{|l|l|l|l|l|l|l|l|l|l|l|l|l|l|}
\hline Parameter & \multicolumn{1}{|c|}{ Jan } & Feb & Mar & Apr & May & Jun & \multicolumn{1}{c|}{ Jul } & Aug & Sep & Oct & Nov & Dec & TAV \\
\hline$\dot{\mathrm{T}}_{\text {AV }}\left({ }_{\mathrm{C}} \mathrm{C}\right)$ & 26.7 & 27.9 & 28.7 & 27.3 & 26.4 & 25.2 & 24.4 & 24.0 & 24.5 & 25.1 & 26.6 & 26.4 & 26.1 \\
\hline$\dot{\mathrm{H}}_{(\mathrm{AV}}(\%)$ & 50.1 & 64.9 & 62.6 & 71.7 & 76.9 & 80.1 & 82.3 & 84.0 & 82.3 & 80.2 & 69.2 & 46.6 & 70.9 \\
\hline $\mathrm{R}_{\tau}$ & 1.1 & 1.1 & 0.6 & 1.4 & 1.1 & 0.6 & 0.6 & 0.5 & 0.2 & 0.6 & 1.3 & 0.6 & 0.8 \\
\hline $\mathrm{R}_{-}$ & 25.8 & 8.0 & 7.2 & 3.5 & 1.8 & 1.5 & 2.8 & 1.1 & 1.0 & 2.5 & 15.9 & 15.4 & 7.2 \\
\hline
\end{tabular}

Also, the yearly average daily temperature $T\left({ }^{0} \mathrm{C}\right)$ and relative humidity $H(\%)$ for the years under investigation can be tabulated as follows:

Table 7: Yearly average daily temperature $\mathbf{T}\left({ }^{0} \mathrm{C}\right)$ and relative humidity $\boldsymbol{H}(\%)$

\begin{tabular}{|c|c|c|}
\hline Year & $\mathbf{T}\left({ }^{0} \mathrm{C}\right)$ & $\boldsymbol{H}(\%)$ \\
\hline 2010 & 25.8 & 72.7 \\
\hline 2011 & 26.5 & 71.4 \\
\hline 2012 & 26.1 & 68.7 \\
\hline Total Average & 26.1 & 70.9 \\
\hline
\end{tabular}

\subsection{The Upper and Lower Limits:}

The upper and lower limits of the climatic parameters were obtained using Statistical Control Charts by the following equations:

$\mathrm{UL}_{\dot{\mathrm{x}}}=\ddot{\mathrm{X}}+\sigma \delta_{\dot{\mathrm{x}}}$

$L L_{\dot{x}}=\ddot{X}-\sigma \delta_{\dot{x}}$

$\delta_{\dot{x}}=\left(1 / \mathrm{n}^{0.5}\right)\left\{\left[\left(\Sigma\left(\dot{X}_{\mathrm{i}}-\ddot{\mathrm{X}}\right)^{2}\right) /(\mathrm{m}-1)\right]^{0.5}\right\}$

Where $\mathrm{UL}_{\dot{\mathrm{x}}}=$ Upper limit; $\mathrm{LL}_{\dot{\mathrm{x}}}=$ Lower limit.

Grand average $(\ddot{X})=$ Total average value $($ TAV $)$

Sample average $(\dot{X})=$ Monthly average value $(\mathrm{AV})$

Number of normal standard deviations $(\sigma)=2$ for $95.5 \%$ confidence, and 3 for $97.73 \%$.

$\delta_{\dot{x}}=$ Standard deviation of the sample means. Sample size $(n)=3$.

Number of Samples $(\mathrm{m})=12$ months.

Thus for the temperature's upper \& lower limits: $\ddot{X}=26.1 ; \sigma=3 ; \& \delta_{\dot{x}}=0.9$.

Hence $\mathrm{UL}_{\dot{\mathrm{x}}}=26.1+3 \times 0.9=28.8^{\circ} \mathrm{C}$.

$$
\mathrm{LL}_{\dot{\mathrm{x}}}=26.1-3 \times 0.9=23.4^{\circ} \mathrm{C} \text {. }
$$

For the relative. humidity's upper \& lower limits: $\ddot{\mathrm{X}}=70.9 ; \sigma=3 ; \& \delta_{\dot{\mathrm{x}}}=7.4$.

Hence $\mathrm{UL}_{\dot{\mathrm{x}}}=70.9+3 \times 7.4=93.1 \%$.

$$
\mathrm{LL}_{\dot{\mathrm{x}}}=70.9-3 \times 7.4=48.7 \% \text {. }
$$

Since $\mathrm{LL}_{\dot{\mathrm{x}}}=48.7 \%>46.6 \%$, thus using the tabular method of statistical chart control, the upper and lower limits can be obtained using the following equations:

For $\dot{X}$ chart:

$\mathrm{UL}_{\dot{\mathrm{x}}}=\ddot{\mathrm{X}}+\mathrm{A}_{2} \dot{\mathrm{R}}$

$\mathrm{LL}_{\dot{\mathrm{x}}}=\ddot{\mathrm{X}}-\mathrm{A}_{2} \dot{\mathrm{R}}$

For $\dot{R}$ chart:

$\mathrm{UL}_{\dot{\mathrm{R}}}=\mathrm{D}_{4} \dot{\mathrm{R}}$

$\mathrm{LL}_{\dot{\mathrm{R}}}=\mathrm{D}_{3} \dot{\mathrm{R}}$

Where $\mathrm{A}_{2}=1.02, \mathrm{D}_{4}=2.57$, and $\mathrm{D}_{3}=0$, these are constants that depends on the sampling size and standard deviation control limits. Since $\mathrm{D}_{3}=0, \mathrm{LL}_{\dot{\mathrm{R}}}=\mathrm{D}_{3} \dot{\mathrm{R}}$ is invalid.

For temperature: $\mathrm{UL}_{\dot{\mathrm{x}}}=26.1+1.02 \times 0.8=26.9^{\circ} \mathrm{C} ; \mathrm{UL}_{\dot{\mathrm{R}}}=2.57 \times 0.8=2.1$

$$
\mathrm{LL} \dot{x}=26.1-1.02 \times 0.8=25.3^{\circ} \mathrm{C} \text {. }
$$

Thus overall control limits can be derived from:

$\mathrm{UL}=\mathrm{UL}_{\dot{\mathrm{x}}}+\mathrm{UL}_{\mathrm{R}}=26.9+2.1=29.0$

$\mathrm{LL}=\mathrm{LL}_{\dot{\mathrm{x}}}-\mathrm{UL}_{\mathrm{R}}=25.3-2.1=23.2$

For rel. humidity: $\mathrm{UL}_{\dot{\mathrm{x}}}=70.9+1.02 \times 7.2=78.2 \% ; \mathrm{UL}_{\dot{\mathrm{R}}}=2.57 \times 7.2=18.5 \%$

$$
\mathrm{LL}_{\dot{\mathrm{x}}}=70.9-1.02 \times 7.2=63.6 \%
$$

Thus overall control limits can be derived from:

$\mathrm{UL}=\mathrm{UL}_{\dot{\mathrm{x}}}+\mathrm{UL}_{\mathrm{R}}=78.2+18.5=96.7$

$\mathrm{LL}=\mathrm{LL}_{\dot{x}}-\mathrm{UL}_{\mathrm{R}}=63.6-18.5=45.1$ 
Performance Evaluation of a Gas Turbine Power Plant by the application of Compressor Off-Line

Table 8: Grand average values, upper and lower limits of the climatic parameters.

\begin{tabular}{|l|l|l|l|}
\hline Parameter & Grand Average & UL & LL \\
\hline $\mathrm{T}\left({ }^{\circ} \mathrm{C}\right)$ & 26.1 & 29.0 & 23.2 \\
$\mathrm{H}(\%)$ & 70.9 & 96.7 & 45.1 \\
\hline
\end{tabular}

Since all the average values in Table 2 falls between the UL \& LL, thus $97.5 \%$ of the climatic parameters will be between these limits.

Table 9: Variations in monthly average daily temperature and relative humidity.

\begin{tabular}{|c|c|c|c|c|c|c|c|c|c|c|c|c|c|}
\hline $\operatorname{Dev} .(\%)$ & Year & Jan & Feb & Mar & Apr & May & Jun & Jul & Aug & Sep & Oct & Nov & Dec \\
\hline \multirow{3}{*}{$\mathrm{D}_{0}$} & 2009 & -47.0 & -45.0 & -43.2 & -46.6 & -48.4 & -50.4 & -52.0 & -52.2 & -50.8 & -50.6 & -48.6 & -46.6 \\
\hline & 2010 & -45.4 & -42.8 & -42.0 & -43.8 & -46.2 & -49.2 & -51.0 & -51.4 & -51.2 & -49.4 & -45.0 & -47.0 \\
\hline & 2011 & -47.6 & -44.8 & -42.6 & -45.6 & -47.0 & -49.2 & -50.8 & -52.4 & -50.8 & -49.4 & -46.8 & -47.8 \\
\hline \multirow{3}{*}{$\mathrm{D}_{0(180)}$} & 2009 & 76.6 & 83.3 & 89.3 & 78.0 & 72.0 & 65.3 & 60.0 & 59.3 & 64.0 & 64.7 & 71.3 & 78.0 \\
\hline & 2010 & 82.0 & 90.7 & 93.3 & 87.3 & 79.3 & 69.3 & 63.0 & 62.0 & 62.7 & 68.7 & 83.3 & 76.7 \\
\hline & 2011 & 74.7 & 84.0 & 91.3 & 81.3 & 76.7 & 69.3 & 64.0 & 58.7 & 64.0 & 68.7 & 77.3 & 74.0 \\
\hline \multirow{3}{*}{$D_{1}$} & 2009 & 103.3 & 126.0 & 113.0 & 144.0 & 159.7 & 167.0 & 179.7 & 182.3 & 174.7 & 172.0 & 109.3 & 75.7 \\
\hline & 2010 & 80.3 & 99.3 & 94.3 & 132.3 & 155.7 & 169.7 & 173.3 & 178.7 & 176.0 & 166.3 & 162.3 & 65.7 \\
\hline & 2011 & 17.3 & 123.7 & 118.3 & 140.3 & 153.7 & 164.7 & 170.3 & 179.3 & 172.7 & 163.7 & 120.3 & 24.3 \\
\hline \multirow{3}{*}{$\mathrm{D}_{1(180)}$} & 2009 & 1.7 & 13.0 & 6.5 & 22.0 & 29.8 & 33.5 & 39.8 & 41.2 & 37.3 & 36.0 & 4.7 & -12.2 \\
\hline & 2010 & -9.8 & -0.3 & -2.8 & 16.2 & 27.8 & 34.8 & 36.7 & 39.3 & 38.0 & 33.2 & 31.2 & -17.2 \\
\hline & 2011 & -41.3 & 11.8 & 9.2 & 20.2 & 26.8 & 32.3 & 35.2 & 39.7 & 36.3 & 31.8 & 10.2 & -37.8 \\
\hline
\end{tabular}

$\mathrm{D}_{0}=$ Deviation $(\%)$ from the design inlet temp. $\left(50^{\circ} \mathrm{C}\right) ; \mathrm{D}_{0 \text { (ISO) }}=$ Deviation $(\%)$ from the ISO inlet temp. $\left(15^{\circ} \mathrm{C}\right)$; $\mathrm{D}_{1}=$ Deviation $(\%)$ from the design relative humidity $(30 \%) ; \mathrm{D}_{1(\mathrm{ISO})}=$ Deviation $(\%)$ from the ISO relative humidity $(60 \%)$

Thus the average values and the total average values of the above parameters are shown in table 10

Table 10: Average values of variations in monthly average daily temp. and relative humidity.

\begin{tabular}{|c|c|c|c|c|c|c|c|c|c|c|c|c|c|}
\hline $\operatorname{Dev} .(\%)$ & Jan & $\mathrm{Feb}$ & Mar & Apr & May & Jun & Jul & Aug & Sep & Oct & Nov & Dec & ATV \\
\hline $\mathrm{D}_{0(A Y)}$ & -46.7 & -44.2 & -42.6 & -45.3 & -47.1 & -49.6 & -51.3 & -52.0 & -50.9 & -49.8 & -46.8 & -47.1 & -47.8 \\
\hline $\mathrm{D}_{0(A \cup)(90)}$ & 77.8 & 86.0 & 91.3 & 82.2 & 76.0 & 68.0 & 62.4 & 60.0 & 63.6 & 67.4 & 77.3 & 76.2 & 74.0 \\
\hline $\mathrm{D}_{1(\mathrm{AV})}$ & 67.0 & 116.3 & 108.5 & 138.9 & 156.4 & 167.1 & 174.4 & 180.1 & 174.5 & 167.3 & 130.8 & 55.2 & 136.4 \\
\hline $\mathrm{D}_{\text {yanceo }}$ & -16.5 & 8.4 & 4.3 & 19.5 & 28.1 & 33.5 & 37.2 & 40.1 & 37.2 & 33.7 & 15.4 & -22.4 & 18.20 \\
\hline
\end{tabular}

\subsection{Analysis of Performance Parameters:}

GT1 were maintained by weekly online washing and periodic offline washing (six months interval), whereas GT2 were maintained by periodic offline washing only (four months interval). From table $11 \& 12$ below, $\mathrm{T}_{1}$, $\mathrm{T}_{2}, \mathrm{~T}_{3}, \mathrm{~T}_{4}, \mathrm{P}_{1} \& \mathrm{P}_{2}$ were collated from the generation station over a period of twenty-four months starting from May 2010 to April 2012. While other variables $\left(W_{c}, W_{t}, W_{n e t}, \eta_{c} . \eta_{o}, S F C\right)$, were derived from thermodynamic equations

For Compression process $\mathrm{Cp}=1.005 \mathrm{~kJ} / \mathrm{kgk}, \gamma=1.4$

For Combustion process \& Expansion process $\mathrm{Cp}=1.11 \mathrm{~kJ} / \mathrm{kgk}, \gamma=1.3$

Table 11: Data for GT1 maintained by weekly online washing and periodic offline washing

\begin{tabular}{|c|c|c|c|c|c|c|c|c|c|c|c|c|}
\hline Month & $\mathrm{T}_{1}$ & $\mathrm{~T}_{2}$ & $\mathrm{~T}_{3}$ & $\mathrm{~T}_{4}$ & $\mathrm{P}_{1}$ & $\mathrm{P}_{2}$ & $\mathrm{~W}_{\mathrm{c}}$ & $\mathrm{W}_{\mathrm{t}}$ & $\mathrm{W}_{\text {net }}$ & $\eta_{\mathrm{c}}$ & $\eta_{\mathrm{o}}$ & $\mathrm{SFC}$ \\
\hline May & 298.8 & 636.6 & 1331.1 & 827.6 & 1.013 & 9.99 & 339.5 & 558.9 & 219.4 & 0.817 & 0.285 & 16.41 \\
\hline Jun & 297.8 & 634.4 & 1326.7 & 824.8 & 1.013 & 9.99 & 338.3 & 557.1 & 218.8 & 0.817 & 0.285 & 16.45 \\
\hline Jul & 297.0 & 632.7 & 1323.1 & 822.6 & 1.013 & 9.99 & 337.4 & 555.6 & 218.2 & 0.817 & 0.285 & 16.50 \\
\hline Aug & 296.9 & 632.5 & 1322.7 & 822.3 & 1.013 & 9.99 & 337.3 & 555.4 & 218.1 & 0.817 & 0.285 & 16.51 \\
\hline Sep & 297.6 & 634.0 & 1325.8 & 824.2 & 1.013 & 9.99 & 338.1 & 556.8 & 218.7 & 0.817 & 0.285 & 16.46 \\
\hline Oct & 297.7 & 634.2 & 1326.2 & 824.5 & 1.013 & 9.99 & 338.2 & 556.9 & 218.7 & 0.817 & 0.285 & 16.46 \\
\hline \multicolumn{10}{|c|}{ Periodic Off-line Washing } \\
\hline Nov & 298.7 & 640.9 & 1340.1 & 833.1 & 1.013 & 9.99 & 343.9 & 562.8 & 218.9 & 0.806 & 0.282 & 16.45 \\
\hline Dec & 299.7 & 652.7 & 1364.9 & 848.6 & 1.013 & 10.80 & 354.8 & 573.1 & 218.3 & 0.820 & 0.276 & 16.49 \\
\hline Jan & 300.3 & 654.0 & 1367.6 & 850.3 & 1.013 & 10.80 & 355.5 & 574.2 & 218.7 & 0.821 & 0.276 & 16.46 \\
\hline Feb & 301.6 & 647.1 & 1353.1 & 841.2 & 1.013 & 9.99 & 347.2 & 568.2 & 221.0 & 0.806 & 0.282 & 16.29 \\
\hline Mar & 302.0 & 647.9 & 1354.9 & 842.3 & 1.013 & 9.99 & 347.6 & 569.0 & 221.4 & 0.806 & 0.282 & 16.26 \\
\hline Apr & 301.1 & 643.5 & 1345.7 & 836.6 & 1.013 & 10.11 & 344.1 & 565.1 & 220.9 & 0.818 & 0.283 & 16.30 \\
\hline \multicolumn{10}{|c|}{ Periodic Off-line Washing } \\
\hline May & 299.9 & 639.9 & 1338.2 & 832.0 & 1.013 & 10.05 & 341.7 & 561.9 & 220.2 & 0.817 & 0.284 & 16.35 \\
\hline
\end{tabular}


Performance Evaluation of a Gas Turbine Power Plant by the application of Compressor Off-Line

\begin{tabular}{|c|c|c|c|c|c|c|c|c|c|c|c|c|}
\hline Jun & 298.4 & 635.7 & 1329.3 & 826.5 & 1.013 & 9.99 & 339.0 & 558.2 & 219.2 & 0.817 & 0.285 & 16.42 \\
\hline Jul & 297.5 & 633.8 & 1325.3 & 824.0 & 1.013 & 9.99 & 338.0 & 556.5 & 218.6 & 0.817 & 0.285 & 16.47 \\
\hline Aug & 297.3 & 633.4 & 1324.4 & 823.4 & 1.013 & 9.99 & 337.8 & 556.2 & 218.4 & 0.817 & 0.285 & 16.48 \\
\hline Sep & 297.4 & 633.6 & 1324.9 & 823.7 & 1.013 & 9.99 & 337.9 & 556.3 & 218.5 & 0.817 & 0.285 & 16.48 \\
\hline Oct & 298.3 & 635.5 & 1328.9 & 826.2 & 1.013 & 9.99 & 338.9 & 558.0 & 219.1 & 0.817 & 0.285 & 16.43 \\
\hline \multicolumn{10}{|c|}{ Periodic Off-line Washing } \\
\hline Nov & 300.5 & 640.2 & 1338.7 & 832.3 & 1.013 & 9.99 & 341.4 & 562.1 & 221.8 & 0.817 & 0.285 & 16.23 \\
\hline Dec & 299.5 & 652.3 & 1364.0 & 848.0 & 1.013 & 10.80 & 354.6 & 572.8 & 218.2 & 0.820 & 0.276 & 16.50 \\
\hline Jan & 299.6 & 654.7 & 1369.1 & 851.2 & 1.013 & 10.97 & 357.3 & 574.9 & 217.6 & 0.821 & 0.274 & 16.54 \\
\hline Feb & 300.6 & 642.5 & 1343.5 & 835.2 & 1.013 & 10.11 & 343.6 & 564.1 & 220.6 & 0.818 & 0.284 & 16.32 \\
\hline Mar & 301.7 & 644.8 & 1348.4 & 838.3 & 1.013 & 10.11 & 344.8 & 566.2 & 221.4 & 0.818 & 0.284 & 16.26 \\
\hline Apr & 300.2 & 641.5 & 1341.7 & 834.1 & 1.013 & 10.11 & 343.1 & 563.4 & 220.3 & 0.818 & 0.284 & 16.34 \\
\hline Average value & 640.8 & 1339.9 & 833.0 & - & 10.16 & 343.3 & 562.7 & 219.4 & 0.816 & 0.283 & 16.41 \\
\hline
\end{tabular}

Table 12: Data for GT2 maintained by offline water-washing only.

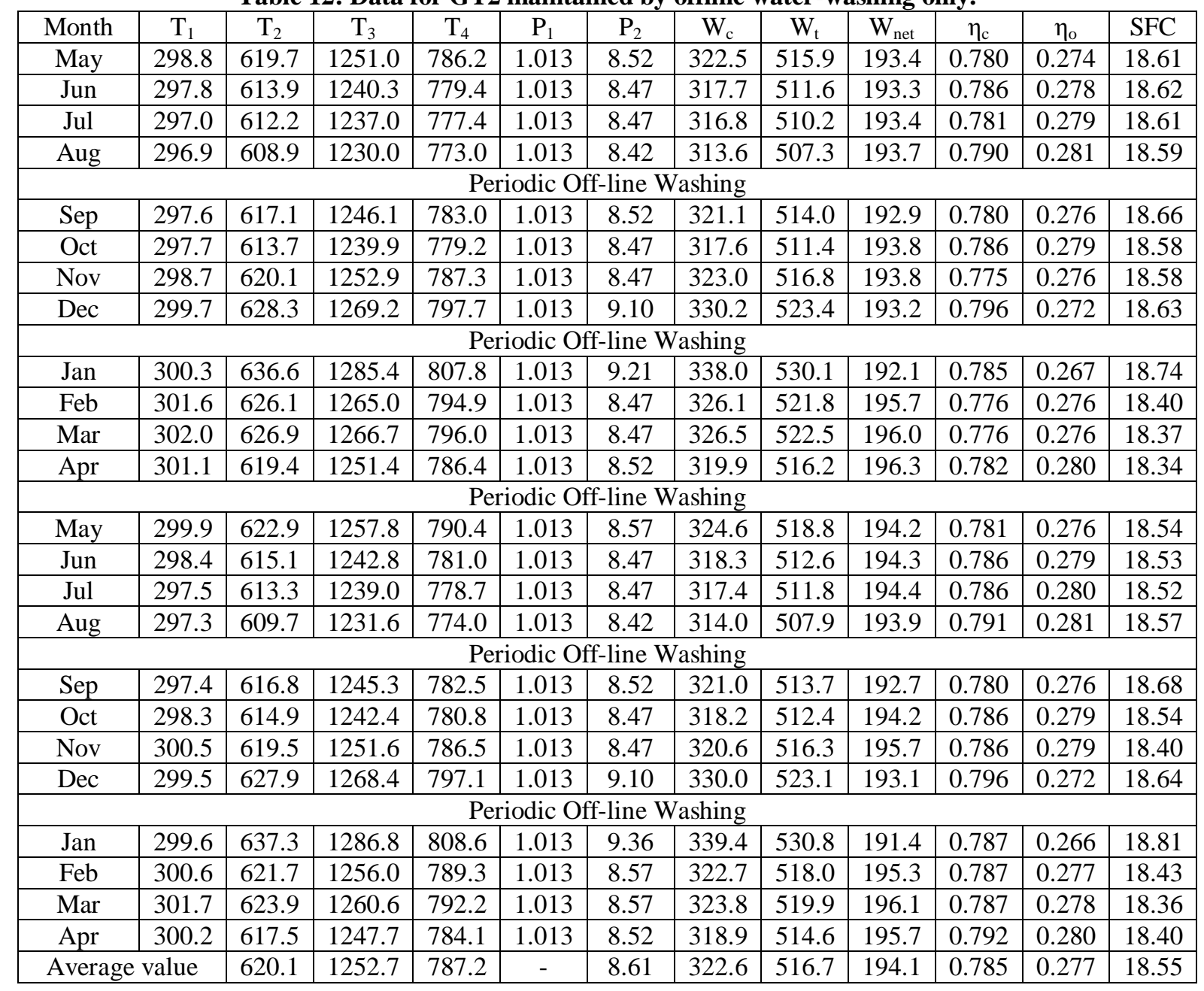

The variation in the average values of the GTs can be tabulated as shown in table 6 below:

\begin{tabular}{|c|c|c|c|c|c|c|c|c|c|}
\hline $\mathrm{T}_{2}$ & $\mathrm{~T}_{3}$ & $\mathrm{~T}_{4}$ & $\mathrm{P}_{2}$ & $\mathrm{~W}_{\mathrm{c}}$ & $\mathrm{W}_{\mathrm{t}}$ & $\mathrm{W}_{\text {net }}$ & $\eta_{\mathrm{c}}$ & $\eta_{\mathrm{o}}$ & $\mathrm{SFC}$ \\
\hline 20.7 & 87.2 & 45.8 & 1.55 & 20.7 & 46.0 & 25.3 & 0.031 & .004 & 2.14 \\
\hline
\end{tabular}




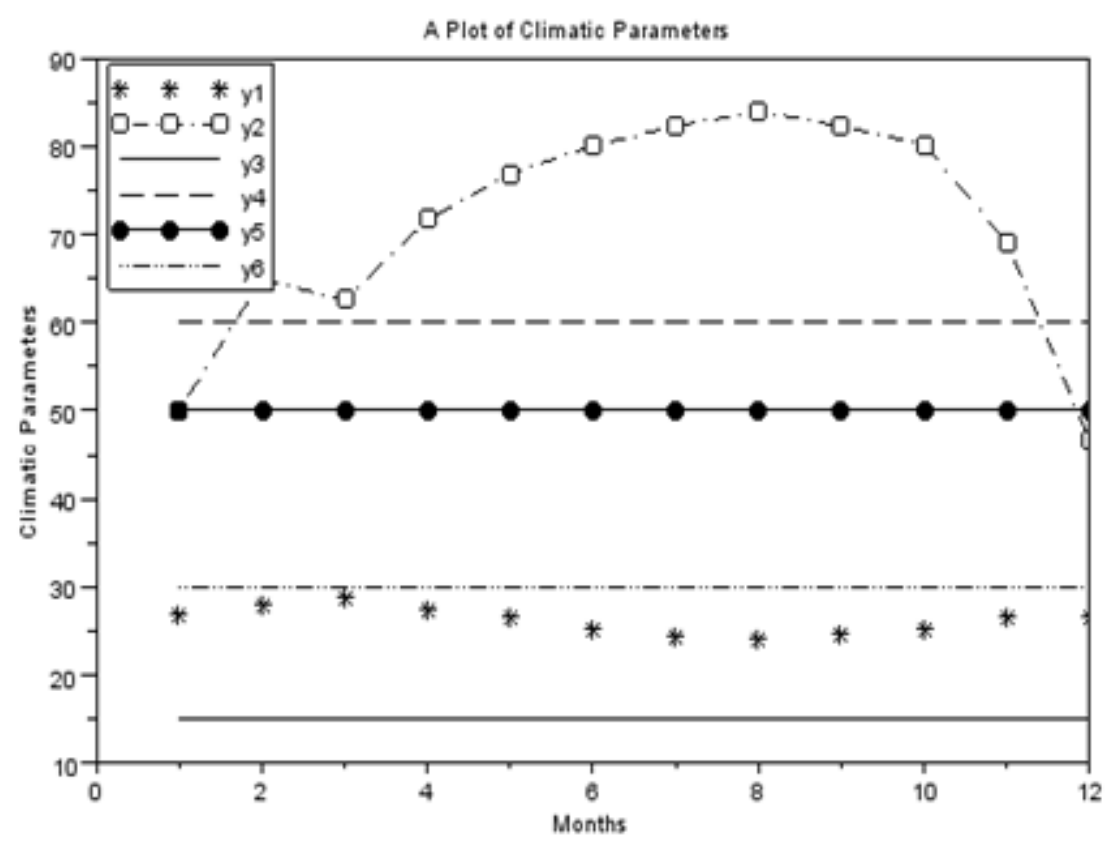

Fig 2 Plot of Climetric Parameters with time (months)

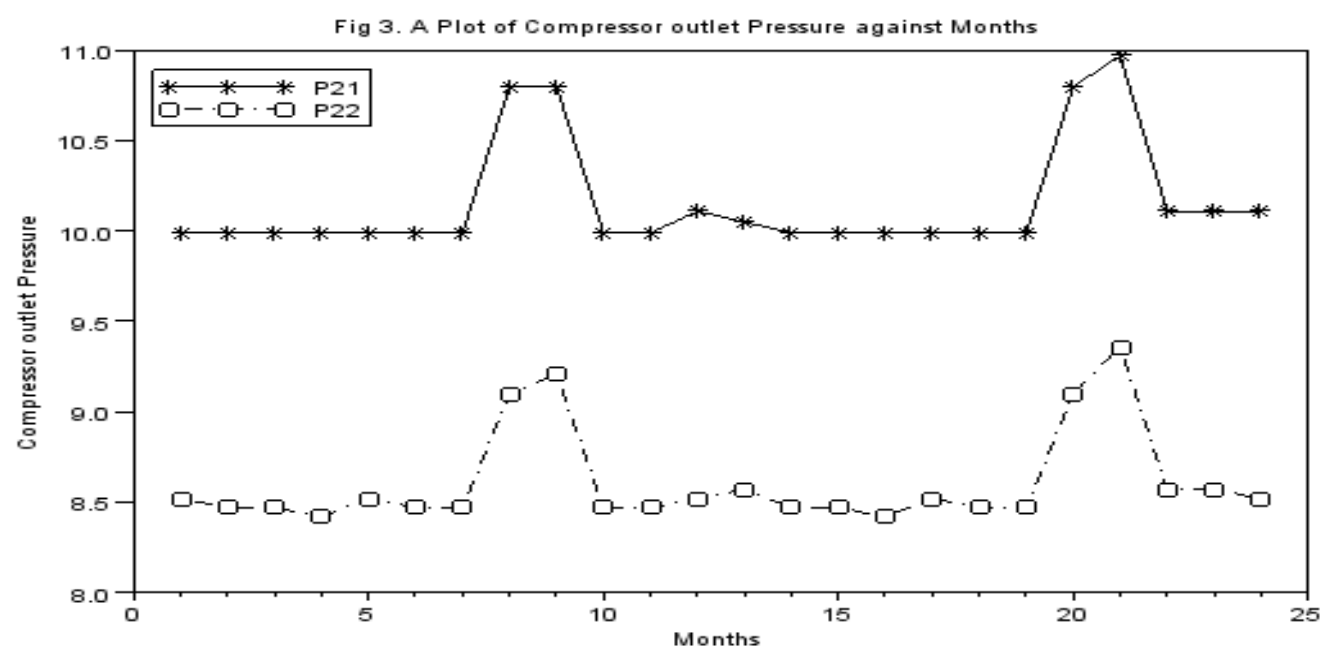

Fig.3 Plot of Compressor outlet pressure with time (months)

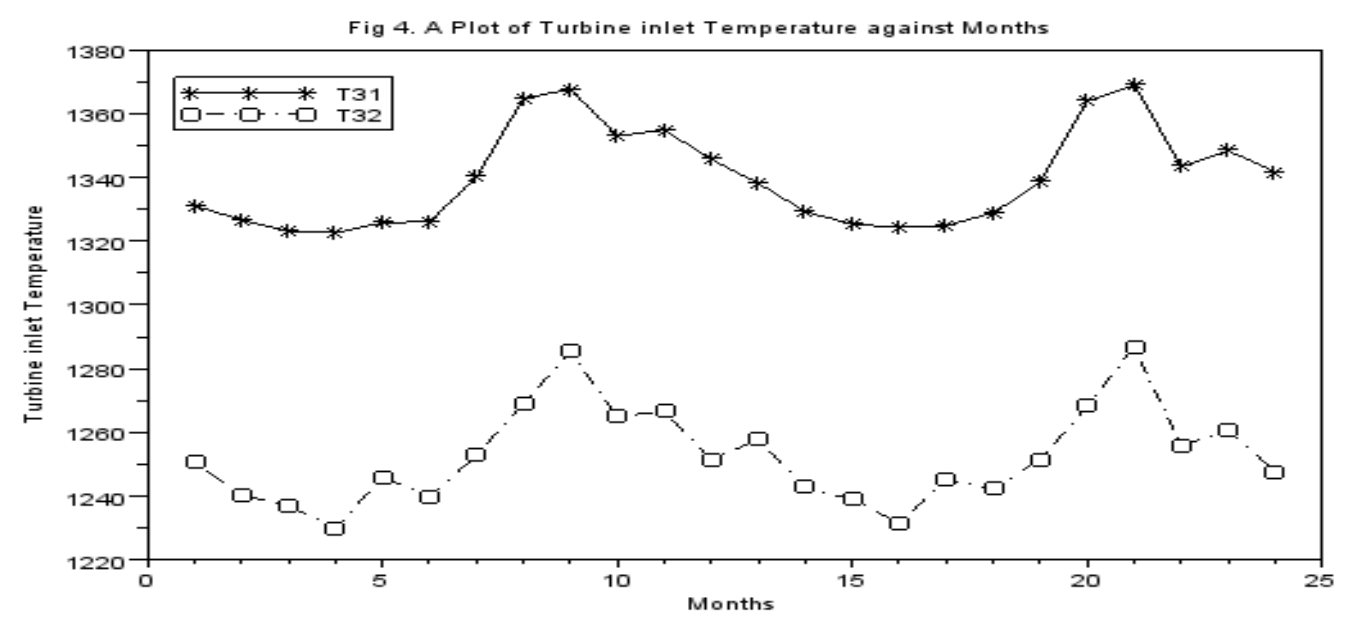

Fig.4 Plot of Turbine inlet temperature with time (months) 


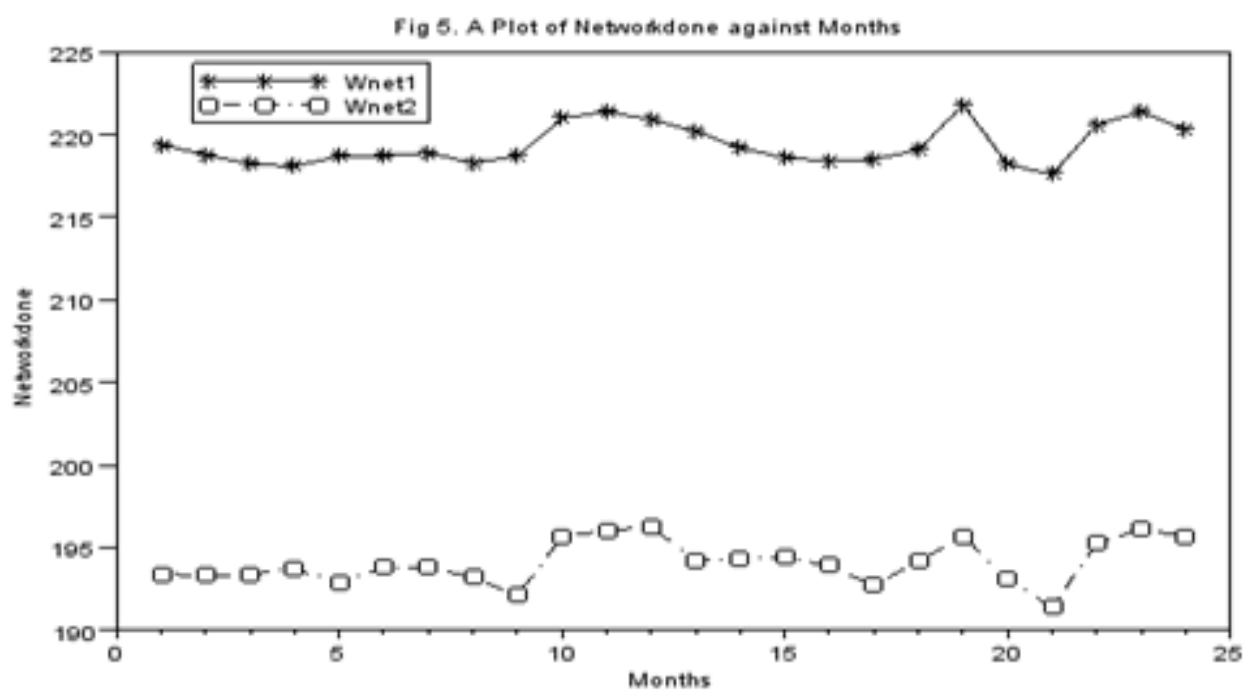

Fig.5 Plot of Network done with time (months)

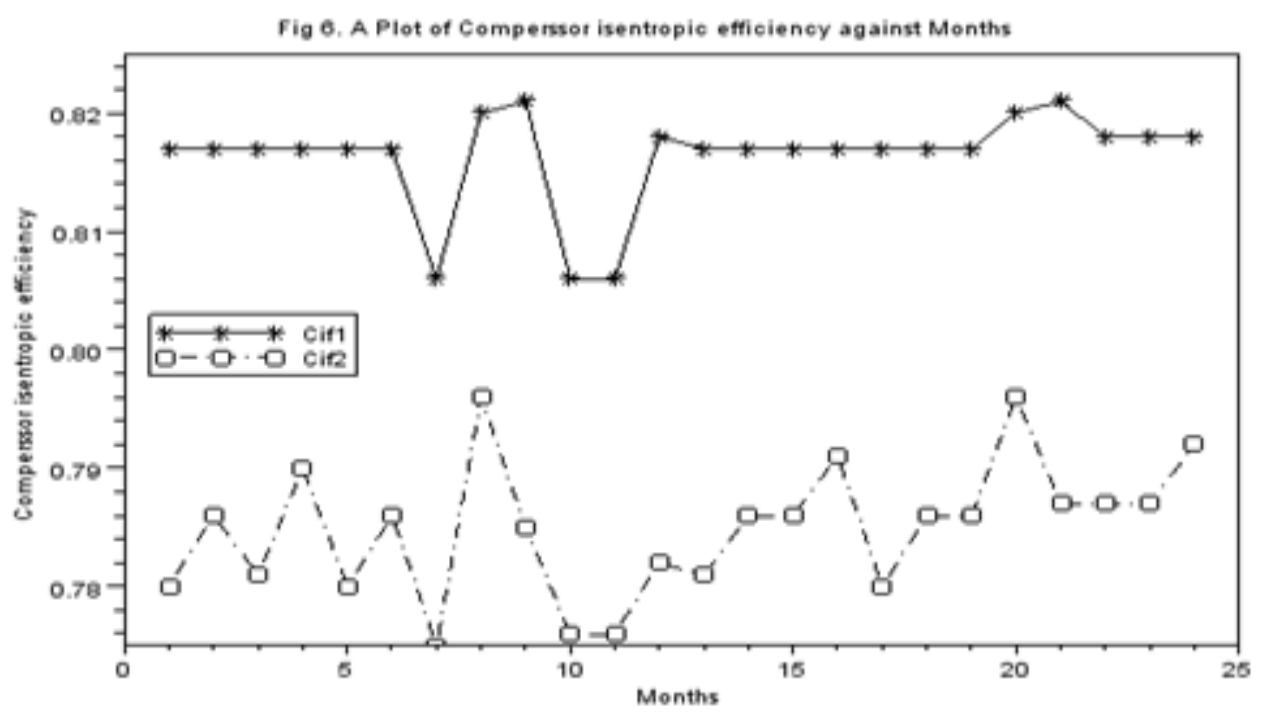

Fig.6 Plot of Compressor isentropic efficiency with time (months)

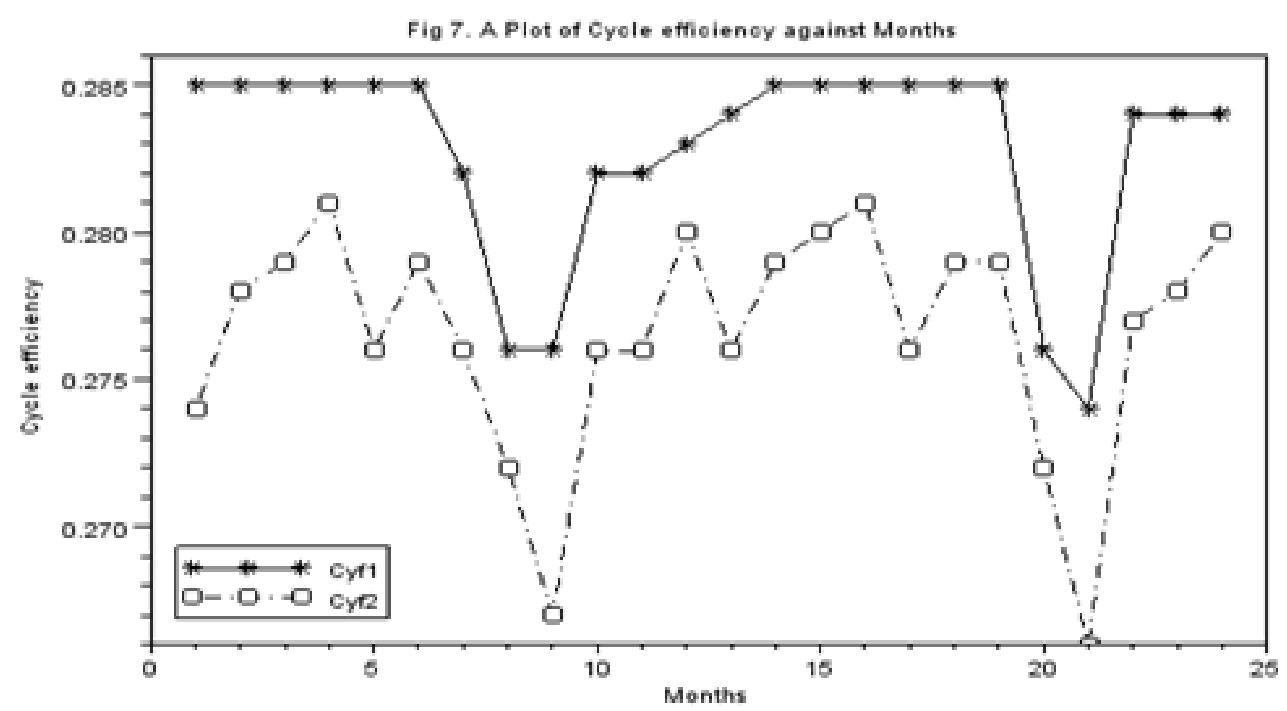

Fig. 7 Plot of Cycle efficiency with time (months) 


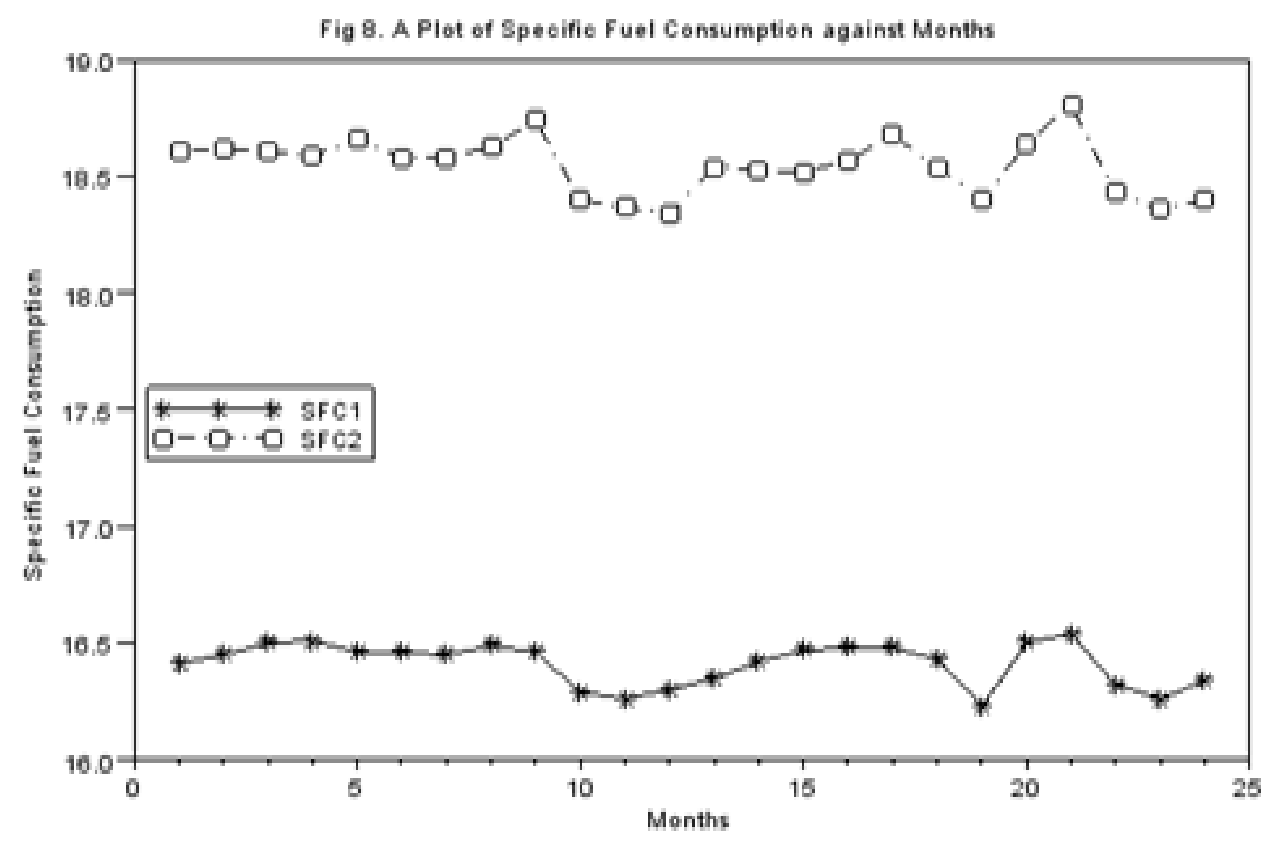

Fig.8 Plot of Specific fuel consumption with time (months)

\section{DISCUSSION OF RESULTS}

The trajectories of the GTs when the monthly daily average compressor outlet pressure is plotted against months are shown in Figure 3. They show that before the offline water washing exercise, GT2 were operating at $8.47 \mathrm{bar}$, as depicted in trend for GT2. The compressor outlet pressure is an indication of fouling, as this menace causes a reduction of the pressure. The application of online water washing to GT1 increases the pressure to 9.99 bar.

The path of the GTs when the turbine inlet temperature is plotted against months is shown in Figure 4. The trend shows that the use of online water washing improved the firing temperature of GT1 by $6.96 \%$.

The graphs of the GTs when the Network output is plotted against months are shown in Figure 5. The trend shows that the use of online water washing improved the Network output of GT1 by $6.42 \%$. The network output momentarily decreases due to re-deposition of foulants in the later stages of the compressor indicating inappropriate application of washing procedure.

The graph of compressor isentropic efficiency is shown in Figure 6. From the graph, GT1 yielded compressor efficiency of $81.6 \%$ as a result of online water washing against the $78.5 \%$ of GT2. It also implies that the air pumping capacity of the GT1 compressor has increased.

The graph of overall GTs operational cycle efficiency is shown in Figure 7. It is observed that a small change of the compressor efficiency have a significant effect on the overall GT performance and efficiency. GT1 has compressor efficiency of $81.6 \%$ which resulted to overall GT efficiency of $28.3 \%$ against $27.7 \%$ of GT2.

The graph of specific fuel consumption is shown in Figure 8. From the graph, GT1 fuel consumption was less by $2.14 \mathrm{~kg} / \mathrm{kwh}$ as a result of online water washing against the $18.55 \mathrm{~kg} / \mathrm{kwh}$ of GT2.

\section{CONCLUSION}

A comparative analysis has been carried out on two GTs on industrial duty for electricity generation. These GTs were commissioned at the same time before the research was carried out on them. Compressor online washing was applied on GT1 and later a combination of compressor hand cleaning of IGVs and offline water washing was also applied to GT1 during shutdown while only compressor hand cleaning of IGVs and offline water washing was applied on GT2. The recovery effect of performance parameters through the use of water washing optimization was significant. The exercise lasted for twenty-four months. The result of the analysis shows that with the use of compressor online water washing on GT1 yielded a compressor efficiency of $81.6 \%$ and overall operational efficiency of $28.3 \%$, the results are handy to conclude that an acceptable balance between these maintenance and operational practices improves the GTs performance and optimize their availability. 


\section{REFERENCES}

[1] Engdar, D (2004) 'Gas Turbines Axial Compressor Fouling and Washing". Proceeding of the Thirty Third Turbo - Machinery Symposium , U. S. A

[2] Cyrus B. Meher-Homji \& Andrew Bromley (2004), "Gas Turbine Axial Compressor Fouling and Washing". Proceeding of the Thirty Third Turbo-machinery Symposium U. S. A.

[3] Ezenwa Alfred Ogbonnaya (2011), "Gas Turbine Performance Optimization using Compressor Online Water Washing Technique”. doi: 10.4263/eng.2011.35058. (http:/www.SciRP.Org/journal/eng).

[4] Elisabeth Syverud (2007), "Axial Compressor Performance Deterioration and Recovery through Online Washing". A Ph.D Thesis, Department of Energy and Process Engineering. Norwegian University of Science and Technology, Norway.

[5] Tarabrin A.P., Bodrou A.I., Schurovsky .V.A, and Stalder, J.P (1996), "An analysis of Axial Compressor Fouling and a cleaning method of their Blading", ASME International Gas

[6] Turbine and Aero engine congress, Birmingham, United Kingdom, ASME Paper No. 96-GT-363. 6. Elisabeth Syverud and Lars E. Bakken (2005) "Online Water Wash Test of GE J85-13". ASME Turbo Expo 2005: Power for Land, Sea and Air. GT 2005-ASME Paper No. GT-2005- 68702.

[7] Howell Hart (1998), "Thermodynamic Appraisal of Gas Turbine Performance in the Niger Delta". A $\mathrm{Ph} . \mathrm{D}$ Thesis, Department of Mechanical Engineering, University of Nigeria Nsukka, Enugu State. 